\title{
Effects of oxonic acid-induced hyperuricemia on mesenteric artery tone and cardiac load in experimental renal insufficiency
}

\author{
Venla Kurra', Tuija Vehmas', Arttu Eräranta ${ }^{1}$, Jarkko Jokihaara², Päivi Pirttiniemi ${ }^{1}$, Heikki Ruskoaho ${ }^{3,4}$, Heikki Tokola ${ }^{3,5}$,
} Onni Niemelä ${ }^{6}$ Jukka Mustonen ${ }^{1,7}$ and Ilkka Pörsti ${ }^{1,7^{*}}$

\begin{abstract}
Background: Recent studies suggest a causal role for increased plasma uric acid in the progression of chronic renal insufficiency (CRI). However, uric acid also functions as an antioxidant with possible beneficial effects.

Methods: We investigated the influence of hyperuricemia on mesenteric arterial tone (main and second order branch) and morphology in experimental CRI. Forty-four Sprague-Dawley rats were 5/6 nephrectomized (NX) or Sham-operated and fed 2.0\% oxonic acid or control diet for 9 weeks.

Results: Oxonic acid feeding elevated plasma uric acid levels 2.4 and 3.6-fold in the NX and Sham groups, respectively. Plasma creatinine and urea were elevated 2-fold and blood pressure increased by $10 \mathrm{mmHg}$ in NX rats, while hyperuricemia did not significantly influence these variables. Right and left ventricular weight, and atrial and B-type natriuretic peptide mRNA content were increased in NX rats, but were not affected by hyperuricemia. In the mesenteric artery, hyperuricemia did not influence vasoconstrictor responses in vitro to norepinephrine or potassium chloride. The small arteries of NX rats featured hypertrophic remodeling independent of uric acid levels: wall to lumen ratio, wall thickness and cross-sectional area were increased without changes in lumen diameter. In the main branch, vasorelaxations to acetylcholine were impaired in NX rats, but were not affected by hyperuricemia. In contrast, relaxations to the large-conductance $\mathrm{Ca}^{2+}$-activated $\mathrm{K}^{+}$-channel (BK $\mathrm{C}_{\mathrm{Ca}}$ ) opener NS-1619 were reduced by oxonic acid feeding, whereas responses to nitroprusside were not affected.
\end{abstract}

Conclusions: Experimental hyperuricemia did not influence cardiac load or vascular remodeling, but impaired BK Ca $_{\text {- }}$-mediated vasorelaxation in experimental $\mathrm{CRI}$.

Keywords: Uric acid, Artery tone, Experimental chronic renal insufficiency, 5/6 nephrectomy, Oxonic acid

\section{Background}

The prevalence of increased plasma uric acid (UA), hyperuricemia, is high in patients with chronic renal insufficiency (CRI). The detrimental effects of hyperuricemia have been linked to cardiovascular complications, as high plasma UA levels commonly predict the development of hypertension [1] and the loss of renal function [2]. To date, however, the contribution of UA to cardiovascular disease has still remained controversial [3].

\footnotetext{
* Correspondence: ilkka.porsti@uta.fi

${ }^{1}$ Department of Internal Medicine, School of Medicine, University of

Tampere, FIN-33014 Tampere, Finland

${ }^{7}$ Department of Internal Medicine, Tampere University Hospital, Tampere, Finland

Full list of author information is available at the end of the article
}

Previous experimental studies, carried out in rats made hyperuricemic by the inhibition of the UA degrading enzyme uricase using dietary $2.0 \%$ oxonic acid, have suggested a causal relationship between high UA and cardiovascular disease [4-7]. UA has been associated with stimulation of the renal renin-angiotensin system (RAS) and reduced nitric oxide (NO) synthesis. These mechanisms may have participated in the subsequent hypertrophic remodeling of the preglomerular arteries, tubulointerstitial damage, and thus predisposed to enhanced sodium retention [4-6,8]. Previously, incubation of the rat aortic rings with UA was found to reduce vasodilatation in response to acetylcholine (Ach) [9], while the endothelial NO production in vitro was 
reduced in hyperuricemic rats [10]. This suggests that the detrimental effects of hyperuricemia may partly result from endothelial dysfunction.

There is an ongoing debate about the role of UA in vascular disease. This arises from the ability of UA to reduce oxidative stress by preventing the superoxide radical from reacting with $\mathrm{NO}$ to generate peroxynitrite [11]. Peroxynitrite can impair NO-mediated relaxation by inhibiting a critical cofactor of the endothelial $\mathrm{NO}$ synthase [12], while it also can modulate vascular tone via smooth muscle [13]. In the aortas of apolipoprotein E-deficient mice, the ability of UA to reduce peroxynitrite levels was associated with improved Ach-elicited relaxation [12]. This result is in agreement with our earlier report that oxonic acid-induced hyperuricemia improved NO-mediated relaxation of the carotid artery in experimental CRI by alleviating oxidative stress [14].

In experimental CRI, reduced vasodilatation via $\mathrm{Ca}^{2+}$-activated $\mathrm{K}^{+}$-channels $\left(\mathrm{BK}_{\mathrm{Ca}}\right)$, observed in isolated mesenteric arterial branches, may precede the elevation of blood pressure (BP) $[15,16]$. However, until now the vascular effects of UA have only been studied in arteries in which the endothelium-mediated dilatation is mainly mediated via NO [12,14]. Here we examined the tone of mesenteric arteries in vitro from the 5/6 nephrectomized (NX) and Sham-operated rats allocated to $2.0 \%$ oxonic acid diet for 9 weeks. Our findings suggest that oxonic acid diet impaired relaxation via $\mathrm{BK}_{\mathrm{Ca}}$ in arterial smooth muscle, but did not significantly affect the endotheliumdependent responses, resistance artery structure, or cardiac load in experimental CRI.

\section{Methods}

\section{Animals and experimental design}

Male Sprague-Dawley rats (weight 335-341 g) were housed in standard animal laboratory conditions with free access to water and food pellets (Lactamin R34, AnalyCen, Lindköping, Sweden) containing 0.9\% calcium, $0.8 \%$ phosphorus, $0.27 \%$ sodium, $0.2 \%$ magnesium, $0.6 \%$ potassium, $1500 \mathrm{IU} / \mathrm{kg}$ vitamin D and $12550 \mathrm{~kJ} / \mathrm{kg}$ energy, $16.5 \%$ protein, $4.0 \%$ fat, $58 \%$ nitrogen-free extract, $3.5 \%$ fiber, $6.0 \%$ ash, and $10 \%$ water. At the age of 8 weeks (study week 0 ), the rats were anesthetized with ketamine/diazepam (75 and $2.5 \mathrm{mg} / \mathrm{kg}$, intraperitoneally, respectively) and NX $(n=22)$ was carried out by the removal of upper and lower poles of the left kidney and the whole right kidney. The sham-operation $(n=22)$ was performed by kidney decapsulation as previously described [15,17]. Antibiotics (metronidazole $60 \mathrm{mg} / \mathrm{kg}$ and cefuroxim $225 \mathrm{mg} / \mathrm{kg}$ ) and pain killers (buprenorphine $0.2 \mathrm{mg} / \mathrm{kg}$ subcutaneously) were given postoperatively three times a day for the total duration of three days. Three weeks after the surgery (study week 3 , i.e. preceding the treatments), the rats were divided into groups (Sham, Sham+Oxo, NX, NX+Oxo) so that systolic BPs, body weights and urine volumes were similar in the two Sham and two NX groups. Oxonic acid (Oxo; 20 g/kg chow, Sigma-Aldrich Chemical Co, St Louis, MO, USA) was then added in the chow of the Sham+Oxo and $\mathrm{NX}+\mathrm{Oxo}$ groups, whereas the Sham and NX groups continued on the normal chow. Hyperuricemia was confirmed by tail vein sampling at study week 5 , and 24 -hour urine was collected in metabolic cages at the end of the 2nd and 11th study weeks [14]. Before and during the treatment period systolic BP was measured at $28^{\circ} \mathrm{C}$ by the tail-cuff method as the averages of five recordings in each rat (Model 129 Blood Pressure Meter; IITC Inc., Woodland Hills, CA, USA). The animals were kept in plastic restrainers during the measurements. To increase the reliability, before the actual measurements the rats were preconditioned on two separate occasions.

After 9 weeks of diets, the rats were weighed and anesthetized (urethane $1.3 \mathrm{~g} / \mathrm{kg}$ ) and blood samples from carotid artery for plasma creatinine, urea and UA were drawn in to chilled tubes with EDTA and heparin as anticoagulants. Blood samples from 2 rats in the Sham group were lost due to technical problems. Plasma creatinine and urea were measured using standard clinical chemical methods (Cobas Integra 800 Clinical Chemical Analyzer, Roche Diagnostics, Basel, Switzerland). UA was measured using an enzymatic colorimetric method [18]. The hearts and the kidneys were removed and weighed. The ventricles were snap frozen in liquid nitrogen-cooled isopentane and stored at $-70^{\circ} \mathrm{C}$ until the extraction of the total RNA. The experimental design of the study was approved by the Animal Experimentation Committee of the University of Tampere, Finland, and the Provincial Government of Western Finland Department of Social Affairs and Health, Finland. The investigation conforms to the Guide for the Care and Use of Laboratory Animals published by the US National Institutes of Health (NIH Publication No. 85-23, revised 1996).

\section{Functional responses and morphology of the mesenteric arterial preparations in vitro}

The experiments on isolated arteries were performed from 10 randomly chosen rats in each group. Two successive ( $3 \mathrm{~mm}$ in length) sections from the main branch of superior mesenteric artery were excised beginning $3 \mathrm{~mm}$ distally from the mesenteric artery-aorta junction, and small (1.9 $\mathrm{mm}$ in length) second order branches were dissected from the mesenteric arterial bed under a microscope (Nikon SMZ-2 T, Nikon Inc., Japan). The endothelium was removed mechanically from the proximal piece of the large artery and from one small arterial ring by perfusing air through the lumen $[15,17]$. In the distal piece of the main branch and in the other small ring the endothelium was left intact. The large arterial 
rings were equilibrated in a resting preload of 4.905 $\mathrm{mN} / \mathrm{mm}$ [16], while the small arterial preparations were normalized so that the internal diameter of the vessel was set at $90 \%$ of that obtained when exposed to intraluminal pressure of $100 \mathrm{mmHg}$ in the relaxed state $[15,17]$. In the large arteries, the force of contraction was measured with isometric force-displacement transducer and registered on a polygraph (FT 03 transducer, 7E Polygraph; Grass Instrument Co., Quincy, MA, USA) and in the small arteries the computerized Mulvany multimyograph (Model 610A, J.P. Trading, Aarhus, Denmark) was employed [16]. All arterial preparations were kept in physiological salt solution (PSS, $\mathrm{pH}$ 7.4) containing $(\mathrm{mM}): \mathrm{NaCl} 119.0, \mathrm{NaHCO}_{3}$ 25.0, glucose 11.1, $\mathrm{CaCl}_{2}$ 1.6, $\mathrm{KCl} 4.7, \mathrm{KH}_{2} \mathrm{PO}_{4} 1.2, \mathrm{MgSO}_{4} 1.2$, and aerated with $95 \% \mathrm{O}_{2}$ and $5 \% \mathrm{CO}_{2}$ at $37^{\circ} \mathrm{C}$.

Contractions were cumulatively elicited in response to norepinephrine (NE) and $\mathrm{KCl}$ in large and small arterial rings. The main branch of the mesenteric artery was chosen for the relaxation responses due to our extensive previous experience with this model [19-22]. Vasodilatation to Ach was investigated in endothelium-intact rings after precontractions with $5 \mu \mathrm{M} \mathrm{NE}$ in the absence and presence of the non-specific nitric oxide synthase (NOS) inhibitor $\mathrm{N}^{\mathrm{G}}$-nitro-L-arginine methyl ester (L-NAME, $0.1 \mathrm{mM}$ ). Responses to the NO donor sodium nitroprusside (NP) and $\mathrm{BK}_{\mathrm{Ca}}$ opener NS-1619 were studied in endothelium-denuded rings precontracted with $\mathrm{KCl}$ [23]. The efficiency of the removal of the endothelium was confirmed by the lack of relaxation to Ach [22]. During the experimental protocol, the rings were allowed a 30 min period at baseline tension in between each of the concentration-response challenges.

Morphology of small arteries at $90 \mathrm{mmHg}$ intraluminal pressure was examined using a pressure myograph (Living Systems Instrumentation, Inc., Burlington, VT, USA), as previously reported [24]. The development of myogenic tone was inhibited by $\mathrm{Ca}^{2+}$-free solution containing $30 \mathrm{mmol} / \mathrm{L}$ EDTA [25]. Small arteries were chosen for the study of morphology due to their contribution to peripheral vascular resistance via remodeling [26].

\section{Ventricular atrial and B-type natriuretic peptide, skeletal a-actin and B-myosin heavy chain mRNAs (ANP, BNP, SkaA and $\beta-M H C$, respectively)}

Total RNA was isolated from the ventricles by the guanidine thiocyanate $\mathrm{CsCl}$ method, and 20- $\mathrm{g}$ samples of RNA were transferred to nylon membranes (Osmonics) for Northern blot analysis as described previously $[27,28]$. Full-length rat ANP cDNA probe (a gift from Dr. Peter Davies, Queen's University, Kingston, Canada), and cDNA probes for rat BNP, Sk $\alpha \mathrm{A}, \beta-\mathrm{MHC}$ and $18 \mathrm{~S}$ were prepared as previously reported $[27,28]$. The cDNA probes were labeled, the membranes were hybridized and washed, and exposed with PhosphorImager screens (Amersham Biosciences), which were scanned with Molecular Imager FX Pro Plus and quantified using Quantity One software (Bio-Rad) as previously described $[27,28]$. The hybridization signals of specific mRNAs were normalized to that of $18 \mathrm{~S}$ RNA in each sample.

\section{Data presentation and analysis of results}

Contractile responses were expressed as maximal wall tensions $(\mathrm{mN} / \mathrm{mm})$ and as a negative logarithm of the agonist concentration producing $50 \%$ of maximal wall tension $\left(\mathrm{pD}_{2}\right)$. Relaxations were depicted as percentage of pre-existing contraction. Statistical comparisons were carried out using one-way and two-way analyses of variance (ANOVA), and the Tukey test was used for post-hoc analyses (SPSS 17.0, SPSS Inc., Chicago, IL, USA). ANOVA for repeated measurements was applied when data consisted of repeated observations at successive observation points. The results were expressed as mean \pm SEM and $\mathrm{P}<0.05$ denoted statistical significance. Unless otherwise indicated, the $P$ values refer to one-way ANOVA.

\section{Drugs}

The drugs used in the present study were: ketamine (Parke-Davis Scandinavia AB, Solna, Sweden), cefuroxim, diazepam (Orion Pharma Ltd., Espoo, Finland), metronidazole (B. Braun AG, Melsungen, Germany), buprenorphine (Reckitt \& Colman, Hull, England), acetylcholine chloride, norepinephrine bitartrate, L-NAME hydrochloride, NS-1619 (Sigma-Aldrich Chemical Co, St Louis, MO, USA), sodium nitroprusside (Fluka Chemie AG, Buchs SG, Switzerland). Stock solutions of the compounds used in the functional arterial experiments were made by dissolving the compounds in distilled water. Solutions were freshly prepared before use and protected from light.

\section{Results}

\section{Blood pressure, body weight, and heart weight}

Systolic BP did not differ in the study groups at the beginning of the oxonic acid diet (Table 1). At the end of the study, mean systolic BP was higher in the two NX groups versus Sham groups $(P=0.041$, two-way ANOVA), and concomitantly increased right and left ventricular weights were also observed. Hyperuricemia did not influence BP or ventricular weights, but was associated with lower final body weight $(\mathrm{P}=0.004$, two-way ANOVA).

\section{Laboratory findings}

Plasma UA was 2.4-fold elevated in the Sham+Oxo and 3.6-fold elevated in the $\mathrm{NX}+\mathrm{Oxo}$ rats when compared with the corresponding controls $(\mathrm{p}=0.005$ and $\mathrm{p}=0.002$, respectively), while subtotal renal ablation did not significantly influence plasma UA levels (Table 1). Plasma 
Table 1 Experimental group data (oxonic acid feeding period from week 3 to 12)

\begin{tabular}{|c|c|c|c|c|}
\hline & Sham & Sham + Oxo & NX & $\mathrm{NX}+\mathrm{Oxo}$ \\
\hline \multicolumn{5}{|l|}{ Systolic blood pressure } \\
\hline Week 3 (before treatment) & $119 \pm 4$ & $120 \pm 5$ & $128 \pm 5$ & $127 \pm 5$ \\
\hline Week 12 & $133 \pm 7$ & $135 \pm 5$ & $141 \pm 6^{\ddagger}$ & $151 \pm 5^{\ddagger}$ \\
\hline \multicolumn{5}{|l|}{ Body weight (g) } \\
\hline Week 3 & $341 \pm 6$ & $337 \pm 8$ & $335 \pm 8$ & $331 \pm 7$ \\
\hline Week 12 & $436 \pm 9$ & $411 \pm 12^{\#}$ & $452 \pm 11$ & $412 \pm 30^{\#}$ \\
\hline \multicolumn{5}{|c|}{ Heart weight $(\mathrm{g} / \mathrm{kg})$ at the end of study } \\
\hline Right ventricle & $0.28 \pm 0.01$ & $0.29 \pm 0.01$ & $0.34 \pm 0.03^{\ddagger}$ & $0.33 \pm 0.03^{\ddagger}$ \\
\hline Left ventricle & $1.71 \pm 0.06$ & $1.86 \pm 0.06$ & $2.23 \pm 0.11^{* \neq}$ & $2.41 \pm 0.18^{*^{\ddagger}}$ \\
\hline Removed kidney tissue (g/kg) & & & $7.67 \pm 0.17$ & $7.50 \pm 0.08$ \\
\hline Uric acid $(\mu \mathrm{mol} / \mathrm{l})$ & $33.5 \pm 11.8$ & $121.6 \pm 22.4^{*}$ & $64.4 \pm 21.0$ & $156.7 \pm 20.2^{* \dagger}$ \\
\hline Creatinine $(\mu \mathrm{mol} / \mathrm{l})$ & $40.1 \pm 5.7$ & $49.3 \pm 3.2$ & $80.7 \pm 3.2^{* \neq}$ & $81.8 \pm 8.8^{* \neq}$ \\
\hline Urea (mmol/l) & $6.5 \pm 0.4$ & $8.3 \pm 0.5$ & $12.9 \pm 0.6^{* \neq}$ & $14.3 \pm 2.2^{* \neq}$ \\
\hline
\end{tabular}

Values are mean $\pm \mathrm{SEM} ; n=11$, except for laboratory values in the Sham group $n=9$. ${ }^{*} P<0.05$ compared with the Sham group, ${ }^{\dagger} P<0.05$ compared with the $\mathrm{NX}$ group using one-way ANOVA; ${ }^{\ddagger} P<0.05 \mathrm{NX}$ groups compared with the Sham groups using two-way ANOVA; ${ }^{\#} P<0.05$ Sham+Oxo and NX+Oxo groups compared with the Sham and NX groups using two-way ANOVA.

creatinine and urea levels were elevated approximately two-fold in the NX groups and were not affected by hyperuricemia.

\section{Ventricular load, as evaluated using ANP, BNP, SkaA and $\beta$-MHC mRNA levels}

The synthesis of right and left ventricular ANP and BNP mRNAs, and left ventricular Sk $\alpha \mathrm{A}$ and $\beta-\mathrm{MHC}$ mRNAs, were clearly higher in the NX groups when compared with the Sham groups $(\mathrm{P}<0.05$ for all, two-way ANOVA) (Figure 1). Oxonic acid feeding did not influence the mRNA levels of these genes.

\section{Functional responses in the main branch of the mesenteric artery}

Contractile sensitivity to NE was slightly higher in the NX groups when compared with the two Sham groups ( $\mathrm{P}<0.001$, two-way ANOVA). However, the difference in the contractions to NE did not curtail the results on vasorelaxation, as the relaxations were elicited after $5 \mu \mathrm{M}$ NE concentration that induced approximately $70-80 \%$ of maximal response in all groups. Responses to $\mathrm{KCl}$ were comparable between NX and Sham rats. The relaxation induced by Ach in the main branch of the mesenteric artery was markedly impaired in the NX groups, while experimental hyperuricemia did not influence these responses either in Sham or NX rats $(\mathrm{P}=0.208 \mathrm{NX}$ versus $\mathrm{NX}+\mathrm{Oxo}$ groups, ANOVA for repeated measurements) (Figure 2A). Inhibition of NOS with L-NAME equally reduced the relaxation to Ach in the Sham and Sham+Oxo groups, while the response was almost abolished in the $\mathrm{NX}$ and $\mathrm{NX}+\mathrm{Oxo}$ groups (Figure 2B). As displayed by the diminished relaxation to NP, vasorelaxation via cGMP in arterial smooth muscle was reduced in the NX groups when compared with the Sham groups $(\mathrm{P}=0.008$, two-way ANOVA for repeated measurements), whereas oxonic acid feeding did not influence this response (Figure 2C). In contrast, vasorelaxation induced by the $\mathrm{BK}_{\mathrm{Ca}}$ opener NS-1619 was significantly reduced in $\mathrm{NX}+\mathrm{Oxo}$ rats when compared with all other groups $(P=0.032$, ANOVA for repeated measurements) (Figure 2D).

\section{Functional responses and morphology of the small mesenteric artery}

In the small arterial rings, maximal wall tension in response to NE was higher in the NX rats than in Sham rats $(\mathrm{P}=0.03$, two-way ANOVA), while the sensitivity to $\mathrm{NE}\left(\mathrm{pD}_{2}\right)$ was similar in all groups (Table 2). Responses to $\mathrm{KCl}$ were comparable between $\mathrm{NX}$ and Sham rats also in the small mesenteric artery. Isolated second order mesenteric artery branches from NX rats exhibited hypertrophic remodeling: increased wall thickness, wall to lumen ratio, and wall cross-sectional area without changes in lumen diameter when compared with Sham rats. Experimental hyperuricemia did not significantly influence the structure of small mesenteric artery (Figure 3).

\section{Discussion}

Oxonic acid-induced hyperuricemia has been widely studied in recent years, but consensus on the putative harmfulness of increased circulating UA concentration still remains elusive. In this study we employed the 5/6 nephrectomy rat model of CRI to investigate the influence of experimental hyperuricemia on the tone and morphology of the mesenteric artery. The NX rats showed 

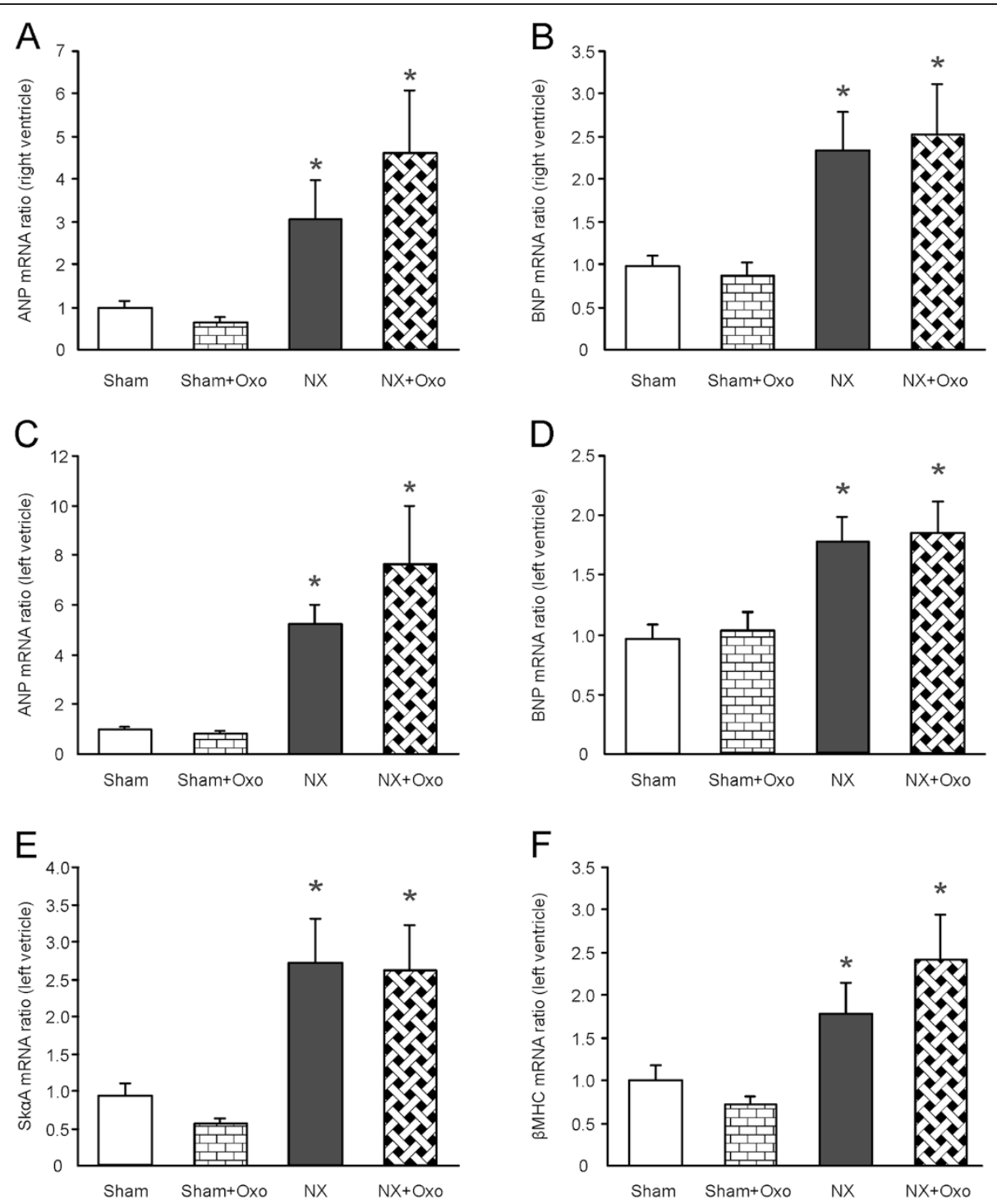

Figure 1 Evaluation of cardiac load. Right ventricular atrial natriuretic peptide (ANP) (A) and B-type natriuretic peptide (BNP) (B); and left ventricular ANP (C), BNP (D), skeletal a-actin (SkaA) (E), and $\beta$-myosin heavy chain ( $\beta$-MHC) (F) mRNAs in the experimental groups; values are mean \pm SEM, $n=11$ for all groups; ${ }^{*} P<0.05$, two-way ANOVA compared with the Sham groups. $N X=5 / 6$ nephrectomized rat, Sham=sham-operated rat, $O x O=2.0 \%$ oxonic acid diet.

several characteristic findings of moderate renal insufficiency [16,29], whereas experimental hyperuricemia did not influence vasoconstrictor responses, renal function, cardiac load, or small artery morphology. To our knowledge, the present study is the first to suggest that hyperuricemia may impair vasorelaxation via $\mathrm{BK}_{\mathrm{Ca}}$, indicating alteration in smooth muscle hyperpolarization.

Oxonic acid feeding inhibits the oxidation of UA to its metabolite, allantoin, resulting in hyperuricemia. In the present study, oxonic acid diet elevated plasma UA 2.4 to 3.6 -fold, which is in line with the 1.3 to 2.8 -fold elevations observed in previous experimental studies [4-6]. The development of stage 2-3 renal insufficiency was confirmed by the elevated levels of plasma creatinine and urea, impaired endothelium-mediated vasodilatation, hypertrophic remodeling of the resistance vessels, and modest elevation of BP [15,29]. Increased right and left ventricular weights, higher ANP and BNP mRNA content, as well as increased left ventricular Sk $\alpha \mathrm{A}$ and $\beta$-MHC mRNA content, indicated permanent volume and pressure overload after subtotal renal ablation [15]. However, hyperuricemia did not significantly influence any of the indicators of cardiac load either in the Sham or NX rats.

Arterial contractions were examined here in order to reveal differences in vasoconstrictor sensitivity that would potentially interfere with the interpretation of the relaxation experiments. No differences were found in responses elicited by membrane depolarisation with $\mathrm{KCl}$ 

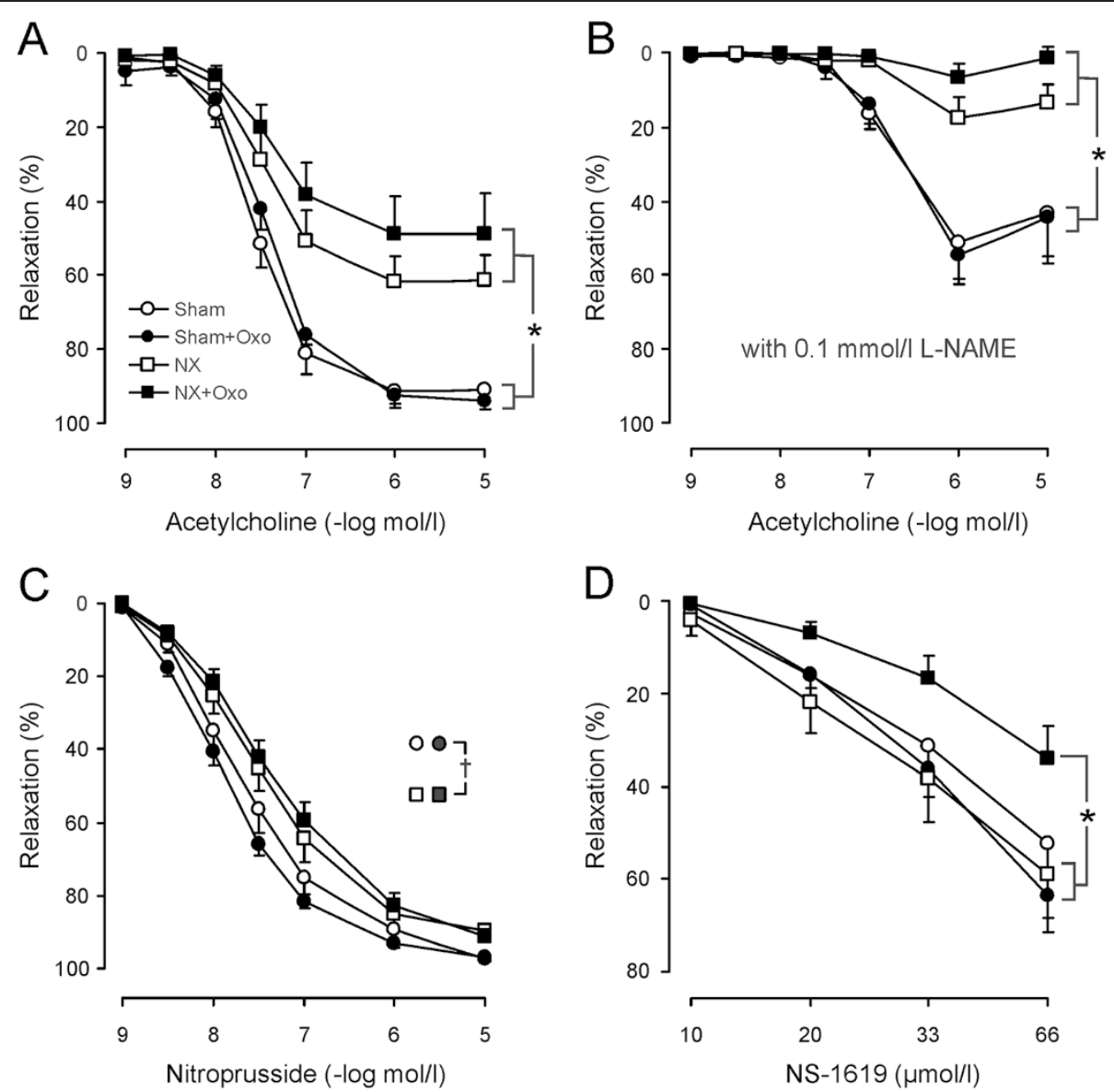

Figure 2 Vasorelaxation in vitro. Line graphs show relaxation responses induced by acetylcholine in the absence (A) and presence (B) of L-NAME, and relaxations elicited by the NO donor nitroprusside (C), and the large conductance calcium-activated potassium channel opener NS-1619 (D) in the experimental groups; values are mean $\pm \mathrm{SEM}, n=10$ for all groups; $* P<0.05$, ANOVA for repeated measurements; ${ }^{\dagger} P<0.05$ NX groups compared with the Sham groups using two-way ANOVA for repeated measurements. Groups as in Figure 1.

(Table 2). In the main branch, NX rats exhibited slightly higher sensitivity but no significant change in maximal response to NE. However, in the small artery the NX groups exhibited slightly higher maximal response without changes in sensitivity to NE. Importantly, oxonic acid feeding did not influence the vasoconstrictor responses either in the second order or main branches of the mesenteric artery. Thus, changes in the vasodilator responses induced by hyperuricemia were not explained by alterations in vasoconstrictor responses.

Oxonic acid feeding did not induce changes in the morphology of small mesenteric arteries, while hypertrophic arterial remodeling was clearly observed in the NX rats [15]. Previously, oxonic acid diet was found to activate renal RAS, as indicated by increased expression of juxtaglomerular renin, and result in hypertrophic remodeling of the glomerular afferent arterioles [5-7,30]. Although local vascular RAS components were not examined here, the oxonic acid model of hyperuricemia is characterized by elevated plasma levels of aldosterone with subsequent sodium retention [8]. The present results suggest that despite possible activation of the circulating RAS, high UA level does not influence the morphology of small arteries and heart.

Vasorelaxation was investigated in the main branch of the mesenteric artery, which functionally resembles the second-order branches in the same arterial bed $[15,16]$. Unlike the rat aorta, where endothelium-dependent vasodilatation is largely mediated via $\mathrm{NO}$, the endotheliumderived relaxation of the mesenteric artery is also mediated by hyperpolarization of smooth muscle [15]. Relaxation to Ach was impaired in NX rats, and the response was practically abolished in the presence of L-NAME in both NX groups, indicating that it was mediated via NO. Inhibition of NOS reduced the relaxation to Ach also in Sham rats, but the vessels showed more pronounced relaxations in the presence of L-NAME than those from NX rats $[15,16]$. The L-NAME resistant vasorelaxation in the rat mesenteric artery has been attributed to endotheliumdependent hyperpolarization [15-17]. In Sham and NX 
Table 2 Parameters of contractile responses of isolated second order branches and the main branch of the mesenteric artery

\begin{tabular}{|c|c|c|c|c|}
\hline & Sham & Sham+Oxo & NX & $\mathrm{NX}+\mathrm{OxO}$ \\
\hline \multicolumn{5}{|l|}{ Small artery } \\
\hline \multicolumn{5}{|l|}{ Norepinephrine } \\
\hline $\mathrm{pD}_{2}(-\log \mathrm{mol} / \mathrm{l})$ & $5.81 \pm 0.08$ & $6.00 \pm 0.09$ & $5.81 \pm 0.09$ & $5.87 \pm 0.11$ \\
\hline Maximal wall tension $(\mathrm{mN} / \mathrm{mm})$ & $5.46 \pm 0.17$ & $5.82 \pm 0.50$ & $6.63 \pm 0.54^{\ddagger}$ & $6.58 \pm 0.39^{\ddagger}$ \\
\hline \multicolumn{5}{|l|}{$\mathrm{KCl}$} \\
\hline $\mathrm{pD}_{2}(-\log \mathrm{mol} / \mathrm{l})$ & $1.41 \pm 0.01$ & $1.42 \pm 0.02$ & $1.39 \pm 0.02$ & $1.39 \pm 0.03$ \\
\hline Maximal wall tension $(\mathrm{mN} / \mathrm{mm})$ & $5.59 \pm 0.43$ & $5.93 \pm 0.56$ & $6.37 \pm 0.49$ & $6.84 \pm 0.32$ \\
\hline \multicolumn{5}{|l|}{ Main branch } \\
\hline \multicolumn{5}{|l|}{ Norepinephrine } \\
\hline $\mathrm{pD}_{2}(-\log \mathrm{mol} / \mathrm{l})$ & $6.26 \pm 0.14$ & $5.97 \pm 0.05$ & $6.49 \pm 0.13^{\ddagger}$ & $6.64 \pm 0.11^{\ddagger}$ \\
\hline Maximal wall tension $(\mathrm{mN} / \mathrm{mm})$ & $7.30 \pm 0.49$ & $8.60 \pm 0.49$ & $9.14 \pm 0.63$ & $9.64 \pm 1.52$ \\
\hline \multicolumn{5}{|l|}{$\mathrm{KCl}$} \\
\hline $\mathrm{pD}_{2}(-\log \mathrm{mol} / \mathrm{l})$ & $1.51 \pm 0.02$ & $1.51 \pm 0.03$ & $1.51 \pm 0.03$ & $1.53 \pm 0.03$ \\
\hline Maximal wall tension $(\mathrm{mN} / \mathrm{mm})$ & $6.79 \pm 0.85$ & $7.01 \pm 0.94$ & $7.53 \pm 0.67$ & $8.02 \pm 0.96$ \\
\hline
\end{tabular}

Values are mean \pm SEM, $n=10$ for all groups. $\mathrm{pD}_{2}$ is the negative logarithm of the concentration of agonist producing $50 \%$ of the maximal response. ${ }^{7} P<0.05 \mathrm{NX}$ groups compared with Sham groups using two-way ANOVA.
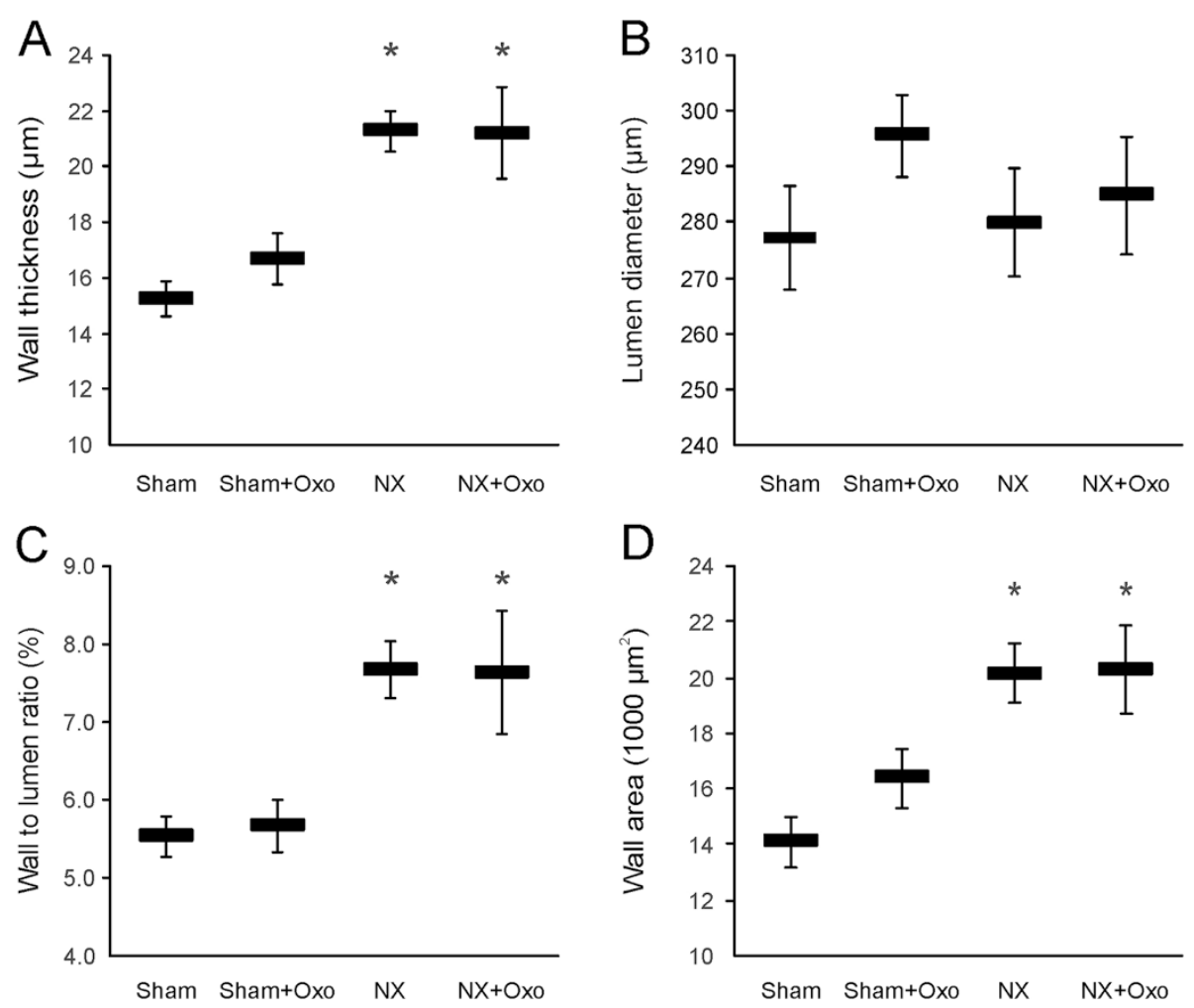

Figure 3 Arterial morphology. Small artery wall thickness ( $\mu \mathrm{m}) \mathbf{( A )}$, lumen diameter ( $\mu \mathrm{m}) \mathbf{( B )}$, wall to lumen ratio (\%) (C), and wall area ( $\left.\mu m^{2}\right)$ (D) at $90 \mathrm{mmHg}$; values are mean $\pm \mathrm{SEM}, n=10$ for all groups; ${ }^{*}<<0.05$ versus Sham. Groups as in Figure 1. 
rats hyperuricemia was without significant influence on the response to Ach, indicating that endotheliumdependent relaxation was not affected by oxonic acid feeding. Vasorelaxation to the exogenous NO donor NP was slightly impaired in the NX groups when compared with the Sham groups, but hyperuricemia did not influence the sensitivity of arterial smooth muscle to relaxation via cGMP.

The present study showed that the endotheliumindependent vasodilatation induced by the $\mathrm{BK}_{\mathrm{Ca}}$ channel opener NS-1619 was impaired in the NX+Oxo group. Notably, this impairment was not observed in Sham+Oxo rats. NS-1619 induces relaxation by triggering intracellular $\mathrm{Ca}^{2+}$ sparks, which induce $\mathrm{K}^{+}$-efflux via $\mathrm{BK}_{\mathrm{Ca}}$ and lead to subsequent hyperpolarization [31-33]. The finding of decreased vasorelaxation sensitivity via $\mathrm{BK}_{\mathrm{Ca}}$ solely in the hyperuricemic NX rats suggests that the effect was specifically associated with the combination of uremic milieu and increased plasma UA concentration.

Several mechanisms could result in alterations of $\mathrm{BK}_{\mathrm{Ca}}$ mediated vascular tone. The $\mathrm{BK}_{\mathrm{Ca}}$ channel, which consists of $\alpha$ - and $\beta 1$-subunits, is the most prominent type of calcium-activated $\mathrm{K}^{+}$channel in arterial smooth muscle [13]. The $\beta 1$-subunit is responsible for tuning the $\mathrm{Ca}^{2+}$-sensitivity [34]. Interaction between the $\alpha$-subunit and $\beta 1$-subunit enhances $\mathrm{Ca}^{2+}$-sensitivity of $\mathrm{BK}_{\mathrm{Ca}}$ channels, whereas the loss of the $\beta 1$-subunit decreases $\mathrm{Ca}^{2+}$ sensitivity [35]. In a recent study using diabetic mice [36], $\mathrm{BK}_{\mathrm{Ca}}$ expression in arterial myocytes was strongly influenced by the calcineurin pathway, which inhibits the expression of the regulatory $\beta 1$-subunit.

Endogenous $\mathrm{BK}_{\mathrm{Ca}}$ inhibitors may influence $\mathrm{K}^{+}$-channel activity. Arachidonic acid metabolites, especially 20hydroxyeicosatetraenoic acid (20-HETE), can inhibit $\mathrm{BK}$ Ca [37]. 20-HETE reduces the open-state probability of the channel [38]. Another endogenous inhibitor of $\mathrm{BK}_{\mathrm{Ca}}$ is hydrogen sulfide, which binds to the $\alpha$-subunit and increases the voltage needed for channel activation [39]. $\mathrm{BK}_{\mathrm{Ca}}$ are also modulated by reactive oxidative species (ROS), which can activate or inactivate $\mathrm{BK}_{\mathrm{Ca}}$ [13]. Such mechanisms are relevant, as elevated UA level following $2.0 \%$ oxonic acid feeding has increased total peroxyl radical-trapping capacity and reduced oxidative stress markers in the rat [14]. Hyperuricemia may increase superoxide dismutase (SOD) activity [40], which catalyzes the dismutation of superoxide $\left(\mathrm{O}_{2}^{-}\right)$into oxygen and hydrogen peroxide $\left(\mathrm{H}_{2} \mathrm{O}_{2}\right)$. UA itself is able to scavenge $\mathrm{BK}_{\mathrm{Ca}}$-inhibiting radicals, and increase the production of $\mathrm{H}_{2} \mathrm{O}_{2}$ by preventing the $\mathrm{H}_{2} \mathrm{O}_{2}$-induced inactivation of SOD [40]. $\mathrm{H}_{2} \mathrm{O}_{2}$ can even induce vasodilatation directly via $\mathrm{BK}_{\mathrm{Ca}}$ activation [41], an effect known to be more pronounced under conditions of reduced NO availability [13]. The latter is a characteristic feature of the uremic milieu [42]. Taken together, a multitude of processes can influence vasorelaxation via $\mathrm{BK}_{\mathrm{Ca}}$, including changes in channel protein gene expression and structure, changes in cellular $\mathrm{Ca}^{2+}$ sparks, levels of ROS, and endogenous $\mathrm{BK}$ Ca inhibitors.

UA is produced from xanthine by the enzyme xantine oxidase, which has been found to play an important role in a variety of tissue and vascular injuries [43]. Although therapeutic interventions with the aim to lower UA with xanthine oxidase inhibitors may be beneficial in treating the vascular disorders associated with renal disease, debate is still ongoing whether the effect is related to lowering UA levels per se, or to reduced xanthine oxidase activity. The present protocol did not include the treatment of hyperuricemia, since the UA-lowering drugs allopurinol, febuxostat and uricosuric agents have been well documented to prevent the pathophysiological changes induced by the oxonic acid feeding [4-6,10,30,44-46].

\section{Conclusions}

We show here that $2.0 \%$ oxonic acid diet increased plasma UA, but did not significantly influence BP, resistance vessel structure, and cardiac load as evidenced by the unaltered ventricular weights and mRNA levels of natriuretic peptides, Sk $\alpha \mathrm{A}$, and $\beta-\mathrm{MHC}$. Hyperuricemia did not influence endothelium-dependent NO-mediated vasorelaxation, but oxonic acid feeding impaired vasorelaxation elicited by the $\mathrm{BK}_{\mathrm{Ca}}$ channel opener NS-1619 in this model of CRI. Future studies are needed to define the molecular mechanisms by which hyperuricemia can influence $\mathrm{BK}_{\mathrm{Ca}}$ function in experimental CRI.

\section{Abbreviations}

20-HETE: 20-hydroxyeicosatetraenoic acid; Ach: Acetylcholine; ANOVA: Analysis of variance; ANP: Atrial natriuretic peptide; $\mathrm{BK}_{\mathrm{Ca}}$ : $\mathrm{Ca}^{2+}$-activated $\mathrm{K}^{+}$-channel; $\beta$-MHC: $ß$-myosin heavy chain; BNP: B-type natriuretic peptide; BP: Blood pressure; CRI: Chronic renal insufficiency; L-NAME: $N^{G}$-nitro-L-arginine methyl ester; NE: Norepinephrine; NO: Nitric oxide; NOS: Nitric oxide synthase; NP: Nitroprusside; NX: 5/6 nephrectomy; Oxo: 2.0\% oxonic acid diet; RAS: Renin-angiotensin system; ROS: Reactive oxygen species; SkaA: Skeletal a-actin; UA: Uric acid.

\section{Competing interests}

The authors declare that they have no competing interests.

\section{Authors' contributions}

VK and TV contributed equally to this article. VK, TV and PP participated in the animal work. VK and TV carried out the in vitro vascular function studies, performed statistical analyses, and drafted the manuscript. AE participated in the animal and laboratory work, statistical analyses, and completed the manuscript with IP. JJ carried out the arterial morphology studies. HR and HT were responsible for the natriuretic peptide, as well as a-actin and ß-myosin determinations. ON carried out the blood and urine analyses. JM participated in the study design, financing, and coordination. IP conceived the study design, participated in the animal work and in vitro vascular function experiments, financed the study, and completed the manuscript. All authors read and approved the final manuscript.

\section{Acknowledgements}

This study was supported by the Competitive State Research Financing of the Expert Responsibility Area of Tampere University Hospital (grant number 9F061), Finnish Foundation for Cardiovascular Research, Finnish Kidney 
Foundation, and Pirkanmaa Regional Fund of the Finnish Cultural Foundation.

\section{Author details}

${ }^{1}$ Department of Internal Medicine, School of Medicine, University of Tampere, FIN-33014 Tampere, Finland. ' Department of Hand Surgery, Tampere University Hospital, Tampere, Finland. ${ }^{3}$ Department of Pharmacology and Toxicology, Institute of Biomedicine, University of Oulu, Oulu, Finland. ${ }^{4}$ Division of Pharmacology and Pharmacotherapy, Faculty of Pharmacy, University of Helsinki, Helsinki, Finland. ${ }^{5}$ Department of Pathology, Oulu University Hospital, Oulu, Finland. ' Department of Clinical Chemistry, Seinäjoki Central Hospital Laboratory, Seinäjoki, Finland. ${ }^{7}$ Department of Internal Medicine, Tampere University Hospital, Tampere, Finland.

Received: 9 September 2014 Accepted: 17 March 2015 Published online: 27 March 2015

\section{References}

1. Forman JP, Choi H, Curhan GC. Plasma uric acid level and risk for incident hypertension among men. J Am Soc Nephrol. 2007;18:287-92.

2. Johnson RJ, Nakagawa T, Jalal D, Sanchez-Lozada LG, Kang DH, Ritz E. Uric acid and chronic kidney disease: which is chasing which? Nephrol Dial Transplant. 2013;28:2221-8.

3. Kanbay M, Segal M, Afsar B, Kang DH, Rodriguez-Iturbe B, Johnson RJ. The role of uric acid in the pathogenesis of human cardiovascular disease. Heart. 2013:99:759-66.

4. Kang DH, Nakagawa T, Feng L, Watanabe S, Han L, Mazzali M, et al. A role for uric acid in the progression of renal disease. J Am Soc Nephrol. 2002;13:2888-97.

5. Sanchez-Lozada LG, Tapia E, Santamaria J, Avila-Casado C, Soto V, Nepomuceno $\mathrm{T}$, et al. Mild hyperuricemia induces vasoconstriction and maintains glomerular hypertension in normal and remnant kidney rats. Kidney Int. 2005;67:237-47.

6. Mazzali M, Kanellis J, Han L, Feng L, Xia YY, Chen Q, et al. Hyperuricemia induces a primary renal arteriolopathy in rats by a blood pressureindependent mechanism. Am J Physiol Renal Physiol. 2002;282:F991-7.

7. Johnson RJ, Herrera-Acosta J, Schreiner GF, Rodriguez-Iturbe B. Subtle acquired renal injury as a mechanism of salt-sensitive hypertension. N Engl J Med. 2002;346:913-23

8. Eräranta A, Kurra V, Tahvanainen AM, Vehmas TI, Kööbi P, Lakkisto P, et al. Oxonic acid-induced hyperuricemia elevates plasma aldosterone in experimental renal insufficiency. J Hypertens. 2008:26:1661-8.

9. Nakagawa T, Hu H, Zharikov S, Tuttle KR, Short RA, Glushakova O, et al. A causal role for uric acid in fructose-induced metabolic syndrome. Am J Physiol Renal Physiol. 2006;290:F625-31.

10. Khosla UM, Zharikov S, Finch JL, Nakagawa T, Roncal C, Mu W, et al. Hyperuricemia induces endothelial dysfunction. Kidney Int. 2005;67:1739-42.

11. Squadrito GL, Cueto R, Splenser AE, Valavanidis A, Zhang H, Uppu RM, et al. Reaction of uric acid with peroxynitrite and implications for the mechanism of neuroprotection by uric acid. Arch Biochem Biophys. 2000;376:333-7.

12. Laursen JB, Somers M, Kurz S, McCann L, Warnholtz A, Freeman BA, et al. Endothelial regulation of vasomotion in apoE-deficient mice: implications for interactions between peroxynitrite and tetrahydrobiopterin. Circulation. 2001;103:1282-8.

13. Gutterman DD, Miura H, Liu Y. Redox modulation of vascular tone: focus of potassium channel mechanisms of dilation. Arterioscler Thromb Vasc Biol. 2005:25:671-8.

14. Kurra V, Eräranta A, Jolma P, Vehmas TI, Riutta A, Moilanen E, et al. Hyperuricemia, oxidative stress, and carotid artery tone in experimental renal insufficiency. Am J Hypertens. 2009;22:964-70.

15. Kööbi P, Kalliovalkama J, Jolma P, Rysä J, Ruskoaho H, Vuolteenaho O, et al. AT1 receptor blockade improves vasorelaxation in experimental renal failure. Hypertension. 2003;41:1364-71.

16. Kööbi $P$, Jolma P, Kalliovalkama J, Tikkanen I, Fan M, Kähönen $M$, et al. Effect of angiotensin II type 1 receptor blockade on conduit artery tone in subtotally nephrectomized rats. Nephron Physiol. 2004;96:p91-8.

17. Jolma $P$, Kööbi $P$, Kalliovalkama J, Saha H, Fan M, Jokihaara J, et al. Treatment of secondary hyperparathyroidism by high calcium diet is associated with enhanced resistance artery relaxation in experimental renal failure. Nephrol Dial Transplant. 2003;18:2560-9.
18. Praetorius E, Poulsen H. Enzymatic determination of uric acid; with detailed directions. Scand J Clin Lab Invest. 1953:5:273-80.

19. Arvola P, Wu X, Kähönen M, Mäkynen H, Riutta A, Mucha I, et al. Exercise enhances vasorelaxation in experimental obesity associated hypertension. Cardiovasc Res. 1999;43:992-1002

20. Mäkynen $H$, Kähönen $M$, Wu X, Arvola P, Pörsti I. Endothelial function in deoxycorticosterone- $\mathrm{NaCl}$ hypertension: effect of calcium supplementation. Circulation. 1996:93:1000-8.

21. Pörsti I, Arvola P, Wuorela H, Vapaatalo H. High calcium diet augments vascular potassium relaxation in hypertensive rats. Hypertension. 1992;19:85-92.

22. Arvola P, Pörsti I, Vuorinen P, Pekki A, Vapaatalo H. Contractions induced by potassium-free solution and potassium relaxation in vascular smooth muscle of hypertensive and normotensive rats. Br J Pharmacol. 1992;106:157-65.

23. Olesen SP, Munch E, Moldt P, Drejer J. Selective activation of $\mathrm{Ca}^{(2+)}$-dependent $\mathrm{K}^{+}$channels by novel benzimidazolone. Eur J Pharmacol. 1994;251:53-9.

24. Suo M, Kalliovalkama J, Pörsti I, Jolma P, Tolvanen JP, Vuolteenaho O, et al, $N(G)$-nitro-L-arginine methyl ester-induced hypertension and natriuretic peptide gene expression: inhibition by angiotensin II type 1 receptor antagonism. J Cardiovasc Pharmacol. 2002;40:478-86.

25. Laurant P, Touyz RM, Schiffrin EL. Effect of pressurization on mechanical properties of mesenteric small arteries from spontaneously hypertensive rats. J Vasc Res. 1997;34:117-25.

26. Schiffrin EL. Remodeling of resistance arteries in essential hypertension and effects of antihypertensive treatment. Am J Hypertens. 2004;17:1192-200.

27. Lako-Futo Z, Szokodi I, Sarman B, Földes G, Tokola H, Ilves M, et al. Evidence for a functional role of angiotensin II type 2 receptor in the cardiac hypertrophic process in vivo in the rat heart. Circulation. 2003:108:2414-22.

28. Pikkarainen S, Tokola H, Kerkelä R, Majalahti-Palviainen T, Vuolteenaho O, Ruskoaho $\mathrm{H}$. Endothelin-1-specific activation of B-type natriuretic peptide gene via p38 mitogen-activated protein kinase and nuclear ETS factors. J Biol Chem. 2003;278:3969-75.

29. Pörsti I, Fan M, Kööbi P, Jolma P, Kalliovalkama J, Vehmas TI, et al. High calcium diet down-regulates kidney angiotensin-converting enzyme in experimental renal failure. Kidney Int. 2004;66:2155-66.

30. Sanchez-Lozada LG, Tapia E, Avila-Casado C, Soto V, Franco M, Santamaria J, et al. Mild hyperuricemia induces glomerular hypertension in normal rats. Am J Physiol Renal Physiol. 2002;283:F1105-10.

31. Brakemeier S, Eichler I, Knorr A, Fassheber T, Kohler R, Hoyer J. Modulation of $\mathrm{Ca}^{2+}$-activated $\mathrm{K}^{+}$channel in renal artery endothelium in situ by nitric oxide and reactive oxygen species. Kidney Int. 2003;64:199-207.

32. Khan RN, Smith SK, Ashford ML. Contribution of calcium-sensitive potassium channels to NS1619-induced relaxation in human pregnant myometrium. Hum Reprod. 1998;13:208-13.

33. Lückhoff A, Busse R. Calcium influx into endothelial cells and formation of endothelium-derived relaxing factor is controlled by the membrane potential. Pflugers Arch. 1990;416:305-11.

34. Brenner R, Perez GJ, Bonev AD, Eckman DM, Kosek JC, Wiler SW, et al. Vasoregulation by the beta1 subunit of the calcium-activated potassium channel. Nature. 2000:407:870-6.

35. Oliveria SF, Dell'Acqua ML, Sather WA. AKAP79/150 anchoring of calcineurin controls neuronal L-type $\mathrm{Ca}^{2+}$ channel activity and nuclear signaling. Neuron. 2007:55:261-75.

36. Nystoriak MA, Nieves-Cintron M, Nygren PJ, Hinke SA, Nichols CB, Chen CY, et al. AKAP150 contributes to enhanced vascular tone by facilitating large-conductance $\mathrm{Ca}^{2+}$-activated $\mathrm{K}^{+}$channel remodeling in hyperglycemia and diabetes mellitus. Circ Res. 2014;114:607-15.

37. Zou AP, Fleming JT, Falck JR, Jacobs ER, Gebremedhin D, Harder DR, et al. 20-HETE is an endogenous inhibitor of the large-conductance $\mathrm{Ca}^{2+}$-activated $\mathrm{K}^{+}$channel in renal arterioles. American Journal of Physiology-Regulatory Integrative and Comparative Physiology. 1996;270:R228-37.

38. Miyata N, Roman RJ. Role of 20-hydroxyeicosatetraenoic acid (20-HETE) in vascular system. J Smooth Muscle Res. 2005:41:175-93.

39. Telezhkin V, Brazier SP, Cayzac S, Muller CT, Riccardi D, Kemp PJ. Hydrogen Sulfide Inhibits Human BK $\left(\mathrm{Ca}_{\mathbf{2}}\right.$ Channels. Arterial Chemoreceptors. 2009;648:65-72.

40. Hink HU, Santanam N, Dikalov S, McCann L, Nguyen AD, Parthasarathy S, et al. Peroxidase properties of extracellular superoxide dismutase: role of uric acid in modulating in vivo activity. Arterioscler Thromb Vasc Biol. 2002;22:1402-8 
41. Wei EP, Kontos HA, Beckman JS. Mechanisms of cerebral vasodilation by superoxide, hydrogen peroxide, and peroxynitrite. Am J Physiol. 1996;271:H1262-6.

42. Vaziri ND, Oveisi F, Ding Y. Role of increased oxygen free radical activity in the pathogenesis of uremic hypertension. Kidney Int. 1998;53:1748-54.

43. Johnson RJ, Kang DH, Feig D, Kivlighn S, Kanellis J, Watanabe S, et al. Is there a pathogenetic role for uric acid in hypertension and cardiovascular and renal disease? Hypertension. 2003:41:1183-90.

44. Sanchez-Lozada LG, Tapia E, Soto V, Avila-Casado C, Franco M, Wessale JL, et al. Effect of febuxostat on the progression of renal disease in $5 / 6$ nephrectomy rats with and without hyperuricemia. Nephron Physiol. 2008;108:p69-78.

45. Nakagawa T, Mazzali M, Kang DH, Kanellis J, Watanabe S, Sanchez-Lozada $L G$, et al. Hyperuricemia causes glomerular hypertrophy in the rat. Am J Nephrol. 2003;23:2-7.

46. Mazzali M, Hughes J, Kim YG, Jefferson JA, Kang DH, Gordon KL, et al. Elevated uric acid increases blood pressure in the rat by a novel crystal-independent mechanism. Hypertension. 2001;38:1101-6.

\section{Submit your next manuscript to BioMed Central and take full advantage of:}

- Convenient online submission

- Thorough peer review

- No space constraints or color figure charges

- Immediate publication on acceptance

- Inclusion in PubMed, CAS, Scopus and Google Scholar

- Research which is freely available for redistribution 